\section{EVOLUTION IN THE PETROLEUM INDUSTRY}

$I^{\mathrm{N}}$ a paper on the above subject read before the Royal Society of Arts on January 21, Mr. James Kewley did not restrict the term 'evolution' to its purely biological sense of adaptation of species of organisms to changing conditions of environment. Rather he gave to it an added significance and power to embrace not only spontaneous changes, but equally predetermined policies designed by man to meet, or even anticipate, commercial and economic demands. Thereafter he proceeded to determine the measure of success achieved within the industry by citation of facts which by their very baldness proclaim the power of such man-made evolution.

In 1895 the deepest well drilled was $1,200 \mathrm{ft}$. Then came the cry for greater production of crude oil. To meet this, deeper and deeper wells were drilled until in 1940 the record was held by one sunk to a depth of $15,000 \mathrm{ft}$., or 2.8 miles. In 1859 the demand was for a reliable and cheap illuminant to replace the vegetable oils then in use. Kerosine fulfilled the demand and remained the chief product of petroleum for nearly forty years.

The next landmark in evolution of the petroleum industry was the incidence of the internal combustion engine, which presented the twofold problem of adequate supply of motor spirit and economic utilization of other crude oil products. Statistics show that in 1915 there were 15.8 tons of crude oil available per automobile registered, and in 1935 only 4.9. Nevertheless the demand for motor spirit was met by increasing its volatility and at the same time the yield of this product from the raw material. Hydrocarbons available in the natural gas from the casing heads of wells and in the gases or uncondensed vapours from distillation plants, for example, pentane and butane, were incorporated in the motor spirit fraction, thus increasing its volatility. Increase in yield by this method, however, was small compared with the impetus given to the industry by development of the cracking process, which proved to be a highly flexible technique both from the point of view of control of yields and character of products obtained. In fact, largely owing to the influence of the cracking process the yield of motor spirit from crude oils has been increased fourfold. In 1910 a yield of 13 per cent was obtained, while in 1940 the estimated figure was 55 per cent.

At this stage parallel evolution in the motor engine industry, involving higher compression ratios, created a demand for motor spirits of higher anti-knock value. That the petroleum industry met this demand is evinced by figures relating to the octane numbers of motor spirits in the United States. In 1931 the antiknock value expressed in terms of octane-number and related to a standard C.F.R. engine was 58 ; in 1933 it was 67 ; and in 1940,73 . It so happened that crude oils produced from fields of younger geological age than those first discovered yielded motor spirits of higher octane number and also that cracking processes produced spirits of better anti-knock value, but whether this had been the case or not, evolution in the petroleum industry would not have been seriously retarded. Large-scale development of dopes, particularly tetra-ethyl lead, would have met the contingency.

Having solved the problem of production of highquality motor spirit, refiners were faced with the difficulty of commercial utilization of the other components of crude oils. Consumers had to be convinced of the practicability of using fuel oil as an alternative to gas, which was in fact much easier to handle. Persistence was rewarded and when the Diesel engine eame upon the scene suitable fuels were already available.

Study of figures for sales of Diesel engines (expressed in horse-power) in the United States indicate how great was the demand for this type of fuel :

$\begin{array}{rrrr}1915 & \ldots & \ldots & 86,000 \\ 1925 & \ldots & \ldots & 536,000 \\ 1935 & \ldots & \ldots & 1,200,000 \\ 1939 & \ldots & \ldots & 2,726,000\end{array}$

The so-called space-heater for domestic purposes created a demand for a distillate intermediate in character between kerosene and gas-oil. The use of asphaltic bitumens for road-making, waterproofing, impregnating and a variety of other purposes became an established fact, and methods of blowing or oxidizing bitumens to suit them for particular applications were gradually perfected.

Then came the call for more and more aviation spirit, a product which had hitherto been considered of negligible importance and the small demand for which had been met by a volatile motor spirit. To-day it is a complex mixture of carefully selected components made by a variety of processes, and refiners are concerned not only with its production in vast quantities, but also in maintaining a high standard of purity.

In the early days of the industry there was a deplorable wastage of natural gas. Now it is harnessed for use in a variety of ways. The dry gas is used as a gaseous fuel in refineries and for industrial purposes, also for the manufacture of hydrogen by thermal decomposition and the production of carbon black by incomplete combustion. Ethane is cracked into the reactive unsaturated hydrocarbon ethylene from which by interaction with iso-butane is obtained neo-hexane, a valuable component of aviation spirit. "Bottled-gas" is produced by liquefaction of butane and propane by pressure at ordinary temperatures and is distributed in steel bottles for domestic cooking and lighting.

Finally, brief mention was made by Mr. Kewley of the ever-increasing number of special oils of the lubricating class, of the numerous new applications of paraffin waxes in the electrical and waterproofing industries, and of the uses to which are put the waste products from various refining processes, for example, naphthenic acids and cresylic acids.

All these data are amassed in support of the main theme of the paper, which is to demonstrate how successfully the petroleum industry has adapted itself to current demands and at the same time to adduce evidence pointing to the maintenance of this process of evolution in all its intricacies.

\section{THE LIGHTNING DISCHARGE}

$A$ $\mathrm{N}$ official communication (Ref. $S / T$ 18a) from the British Electrical and Allied Industries Research Association upon this subject has been published by C. E. R. Bruce and R. H. Golde ( $J$. Inst. Elec. Eng., Pt. II, Dec., 1941). The contribution is an important one, and it presents several new theses. It is considered that the potential requirer to cause a lightning discharge is only a small per 
centage of that hitherto believed necessary, namely, of the order of $5 \times 10^{7}$ volts as compared with Wilson's $1 \times 10^{9}$ to $6 \times 10^{9}$ volts. The energy involved in a flash is of the order of $250 \mathrm{kwh}$. , while the average charge is of the order of 50 coulombs, or 50 per cent greater than had been previously accepted. About one third of this charge is probably neutralized in the intervening space charge.

Available statistical data show that thunderstorms all over the world have similar flash time characteristics and numbers of strokes per flash. Strokes to the Empire State Building, New York, were found to be similar in overall duration to those occurring in ordinary country, due allowance being made for the duration of the initial continuing stroke. The currents in the flashes, however, were greater than those in flashes to normal country. Evidence purporting to suggest that storms in temperate regions vary in the number of strokes per flash was found to be inconclusive, and it is suggested that the later strokes of a flash are less intense than the earlier ones. These successive strokes are initiated by streamers from the original stroke to other cloud centres, and it is thought that strokes to transmission line conductors which do not cause flashover are unlikely to be followed by subsequent strokes.

Support was obtained for the suggestion that the wave forms of atmospherics are due to successive reflexions from the ionosphere and not to current pulsations in the lightning channel.

Negative flashes to earth are more frequent than positive flashes, the ratio being considerably smaller in temperate than in tropical regions. The polarities of direct strokes to transmission lines are unobtainable from magnetic-link observations on transmission towers. A higher proportion of positive currents has been observed by the cathode ray oscillograph as compared with negative currents.

Norinder's values for individual stroke currents are shown to be in error, an important selective principle having been neglected when comparing these with magnetic-link data.

\section{SOUTH AFRICAN PREHISTORY}

A

NUMBER of interesting articles are contained in the Transactions of the Rhodesia Scientific Association, 37 (April, 1941). It is good to learn that the study of the rock-shelter paintings of Southern Rhodesia continues, and the Hon. L. Cripps speaks of thousands of sites of which he has visited and made copies of paintings at some six hundred. This is no mean work, and his little paper, scientifically written so far as it goes, is, one hopes, only the precursor of a larger work. The author has continued to study the superpositions of the different coloured paintings (though making no mention of any changes of style or subject-matter) and by th se means makes out an age-colour sequence not materially differing from that which I was able to suggest in 1928. Further, he considers that the paintings were connected with the burial of the dead, and that the present-day natives are the descendants of the artists. I venture to suggest that some at least of the paintings go back to a very remote period, and that much migration into the country has taken place since they were made. It is always difficult to deny continuity of blood in any given instance, but I doubt whether there is any general direct descent from the earliest painters to the modern inhabitants. Indeed, I am not even sure that the painters in claret were themselves the direct descendants of those who used the earlier colours. May I perhaps remind Mr. Cripps that the problem of dating the paintings will surely involve excavations in the sites and that Bambata and Nswatugi seem to point the way and have in fact already helped in this direction?

Mr. K. Radcliffe-Robinson describes a Stone Age industry from the Wedza district, some three hundred yards from the Sabi River on the banks of a tributary. Dolerite is the chief material used. Implements of various types occur, and, if the industry is really homogeneous, the age cannot be very remote, although some handaxe-like types and a possible burin occur. But so does a polished tool! The occurrence of burins in more or less recent levels has been noted by Schofield in Natal, and rough core tools somewhat of a handaxe type are also not unknown. The technique of polishing is not very common, but examples are known from Southern Rhodesia, and farther to the south, for example, there are local specimens in the Museum at Grahamstown. In no case does this technique appear to be very ancient so far as we can determine. At a part of the site a little distant from the main mass of these tools there was found a Rhodesian Stillbay industry of quartz and ironstone, but owing to the lack of any stratigraphy it is, as is so sadly usual in this country, impossible to prove any relative dating of the two industries. This paper, too, shows a scientific attitude to the problems of Rhodesian prehistory; the draw. ings are adequate but might have been better arranged.

Mr. C. Martin describes pottery-making in Nanyikaland, an art which is apparently dying out. As usual in Bantu tribes, pottery-making is woman's work. A good description and some interesting photographs are given.

\section{C. BURKITT}

\section{DRUG PRODUCTION IN THE BRITISH EMPIRE}

TN a paper on "British Empire Drug Production" 1 before the Royal Society of Arts on December 16 (J. Roy. Soc. Arts, 90, 138; 1942), Dr. Maurice Ashby points out that we are normally dependent on imports from overseas for practically the whole of our requirements of crude drugs, and a large proportion of our pre-war imports came from countries outside the Empire, the continent of Europe being our main source of supply of such vital drugs as belladonna, digitalis, henbane and stramonium. Dr. Ashby, after emphasizing the difficulties which might be encountered, owing to the influence of environment and inherent physiological differences, in growing medicinal plants in a new country where the climate or soil conditions might not be quite the same as in its original home, gave an encouraging account of what is being done in Empire countries to meet essential needs.

In Canada the most important development is the introduction of cascara as a crop, but some years will be required before supplies are available from the new plantings. In Australia and New Zealand the two most important items are agar-agar and ergot, and both Australia and New Zealand appear 